\title{
To Examine the Effect of Inventory Dependent Demand and Time Dependent Holding Cost on Inventory
}

\author{
Pankaj S. Ardak, Atul B. Borade
}

\begin{abstract}
Inventory models are effectively used as control tool in most of the inventory control tools. The current study deals with the inventory production model for non momentary deteriorating items. To developed the mathematical model holding cost is considered as time and demand dependent. The items does not start to deteriorate as soon as it enters into the stock. During stock buildup time demand is assumed to be inventory dependent. Optimum solution has been find out by using differential calculus. Results indicate that total inventory has a major influence of inventory consumption parameter.

KEYWORDS: EPQ, holding cost, Inventory and time dependent consumption rate.
\end{abstract}

\section{INTRODUCTION}

Inventory systems has been studied by many of the researchers by considering different assumptions. Buying capacity of customer increases by the large stock present in the store. Deterioration is common in perishable items like food, milk, meat and flowers. To maintain the quality of such items need special storing arrangement which cause rise in holding cost. As such items deteriorates with time in such condition holding cost vary with time. Ardak et. al. (2017) developed EPQ model for perishable items which required special storing arrangements.[1,2\&3] Items with defect has been analysed without considering inventory carrying cost of imperfect items to developed an EPQ model. [4]. In actual production process the quality of the product depends upon various factors. This can affect the quality of the product hence it is not possible that always good quality items will get produced[5]. In

Revised Manuscript Received on September 15, 2019.

Pankaj S. Ardak: Assit. Prof., P.R. Pote Collège of Engineering and Management ,Amravati India

Dr. Atul B. Borade: Professor, Jawaharlal Darda Institute of Technology, Yavatmal. India

perishable items deterioration start with time. The inventory model with partial backloging has been studied for constant demand.[6]. Rosenblatt and Lee studied inventory model for imperfect production process.[7]. The items deteriorate at higher rate when process change its state., [8]. The total cost is effected by the demand and quality loss function [9]. The optimal production run time get affected by cost of rework, scrap and rate of defective items[10]. Demand was dependent on stock, cusomer and credit policy $[11,12]$. Gede considered stochastic machine unavailability and price- dependent demand to analysed production inventory model[13]. The influence of demand and cost on EPQ has been analysed by Jinn[14]. Set up cost and process quality had a important role in production inventory model [15].

With time perishable items deteriorates, hence in the present study holding cost is considered as time dependent. During stock buildup time demand is assumed to be inventory dependent. Several sections of the paper is divided as following . Mathematical model formulation is in third section.. The numerical and sensitivity analysis had been discussed in last.

The Present model has been developed by considering following Assumptions:-

1. Constant production rate wich is assumed to be greater than Demand.

2. During stock buildup time demand is inventory dependent 
3. Deterioration is non instantaneous and kept constant.

4. As perishable items deteriorates with time.

5. No Shortage.

6. Inspection of all produced items .

\section{NOMENCLATURE}

1. $\mathrm{I}_{1}$ - Inventory with no deterioration

3. $\mathrm{I}_{3}$ - Inventory where demand is considered constant

4. $\mathrm{T}_{1}-$ No deterioration period

5. $\mathrm{T}_{2}$ - Inventory build up time in which deterioration start.

6. $\mathrm{T}_{3}-$ No Inventory build up time.

7. Q-Constant production rate.

8. $\mathrm{R}$-Demand rate.

9. $\theta$-Constant Deterioration rate

10. $\alpha-$ consumption rate of Inventory.

11. HC - Holding cost

12. $\mathrm{C}_{\mathrm{i}-\mathrm{C}}$ Cost of Inspection per unit

13. $\mathrm{T}$ - Production time for each cycle.

14. $\mathrm{C}-$ Cost of Total production

15. IC - Cost of Inspection for all items.

16. TC - Per unit time total cost .

17. A- Cost of set up.

\section{DEVELOPMENT OF MATHEMATICAL MODEL}

Present work develop production inventory model for perishable items with special holding arrangement. Figure 1 shows, the production will start at $\mathrm{t}=0$, upto time $\mathrm{T}_{1}$ the inventory $I_{1}$ builds up with no deterioration. Deterioration start from $\mathrm{T}_{1}$ production stops at time $\mathrm{T}_{2}$. Differential equations to describe the inventory are as follows.

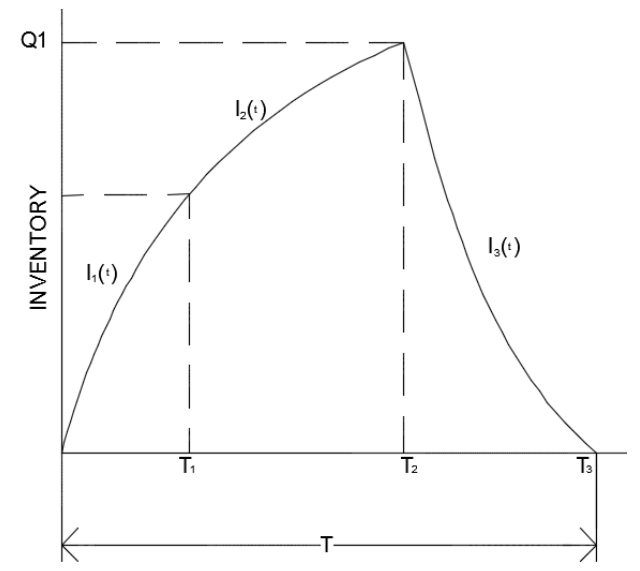

2. $\mathrm{I}_{2}$ - Inventory with deterioration.

Fig. 1. Inventory Level

Change in inventory from time $\mathrm{t}=0$ to $\mathrm{t}=\mathrm{T}_{1}$ is governed by following equation. Here no deterioration.

$\frac{d I_{1}(t)}{d t}=Q-R-\alpha I_{1}(t)$

$$
0 \leq \mathrm{t} \leq \mathrm{T}_{1}
$$

1.

Equation 2 shows the change in inventory from $\mathrm{t}=\mathrm{T}_{1}$ to $\mathrm{t}=$ $\mathrm{T}_{2}$. Here deterioration starts.

$$
\frac{\mathrm{dI}_{2}(\mathrm{t})}{\mathrm{dt}}=\mathrm{Q}-\mathrm{R}-\alpha \mathrm{I}_{2}(\mathrm{t})-\theta \mathrm{I}_{2}(\mathrm{t}) \quad 0 \leq \mathrm{t} \leq \mathrm{T}_{2}
$$

2.

Equation 3 represents the inventory with constant demand and deterioration.

$\frac{\mathrm{dI}_{3}(\mathrm{t})}{\mathrm{dt}}=-\mathrm{R}-\theta \mathrm{I}_{3}(\mathrm{t}) \quad 0 \leq \mathrm{t} \leq \mathrm{T}_{3}$

3.

The solution to above equations are found out by using Initial boundary conditions Inventory $\mathrm{I}_{1}$ will be zero at the start of production system and Maximum at time $\mathrm{T}_{2}$.

$\mathrm{I}_{1}(\mathrm{t})=\frac{\mathrm{Q}-\mathrm{R}}{\alpha}\left[1-\mathrm{e}^{-\alpha \mathrm{t}}\right] \quad 0 \leq \mathrm{t} \leq \mathrm{T}_{1}$

4.

$\mathrm{I}_{2}(\mathrm{t})=\frac{(\mathrm{Q}-\mathrm{R})}{(\alpha+\theta)}+\left[\mathrm{Q}_{1}-\frac{(\mathrm{Q}-\mathrm{R})}{(\alpha+\theta)}\right] \mathrm{e}^{(\alpha+\theta)\left(\mathrm{T}_{2}-\mathrm{t}\right)} \quad 0 \leq \mathrm{t} \leq \mathrm{T}_{2}$

5.

$I_{3}(t)=\frac{R}{\theta}\left[e^{\theta\left(T_{3}-t\right)}-1\right]$

$0 \leq \mathrm{t} \leq \mathrm{T}_{3}$

6.

Total Inventory holding cost is given by

$=\int_{0}^{\mathrm{T}_{1}}(\mathrm{a}+\mathrm{bt}) \mathrm{I}_{1}(\mathrm{t}) \mathrm{dt}+\int_{0}^{\mathrm{T}_{2}}(\mathrm{a}+\mathrm{bt}) \mathrm{I}_{2}(\mathrm{t}) \mathrm{dt}+\int_{0}^{\mathrm{T}_{3}}(\mathrm{a}+\mathrm{bt}) \mathrm{I}_{3}(\mathrm{t}) \mathrm{dt}$

7.

Cost for inspection is given by,

$\mathrm{IC}=\mathrm{C}_{\mathrm{i}}\left(\int_{0}^{\mathrm{T}_{1}} \mathrm{I}_{1}(\mathrm{t}) \mathrm{dt}+\int_{0}^{\mathrm{T}_{2}} \mathrm{I}_{2}(\mathrm{t}) \mathrm{dt}+\int_{0}^{\mathrm{T}_{3}} \mathrm{I}_{3}(\mathrm{t}) \mathrm{dt}+\right)$

8.

Cost for total production is given by

$\mathrm{C}=\mathrm{A}+\mathrm{HC}+\mathrm{IC}$

9.

Cycle time for Production is given by :-

Published By: 
$\mathrm{T}=\mathrm{T}_{1}+\mathrm{T}_{2}\left(1+\frac{\mathrm{Q}-\mathrm{R}}{\mathrm{R}}\right)+\mathrm{T}_{2}^{2}\left[\frac{(\mathrm{Q}-\mathrm{R})}{\mathrm{R}}(\alpha+\theta)\right]$

10.

$\mathrm{TC}=\frac{\mathrm{C}}{\mathrm{T}}$

$$
\mathrm{TC}=\frac{\mathrm{A}+\mathrm{HC}+\mathrm{IC}}{\mathrm{T}_{1}+\mathrm{T}_{2}\left(1+\frac{\mathrm{Q}-\mathrm{R}}{\mathrm{R}}\right)+\mathrm{T}_{2}^{2}\left[\frac{(\mathrm{Q}-\mathrm{R})}{\mathrm{R}}(\alpha+\theta)\right]}
$$

11

$$
\frac{\mathrm{TC}}{\mathrm{T}}=\frac{\mathrm{K}_{1}+\mathrm{T}_{2}^{2} \mathrm{~K}_{2}+\mathrm{T}_{2}^{3} \mathrm{~K}_{3}}{\mathrm{~T}_{1}+\mathrm{T}_{2} \mathrm{~K}_{4}}
$$

\section{2.}

Equation for optimum production up time

$$
\frac{\mathrm{dTCT}}{\mathrm{dT}_{2}}=0
$$

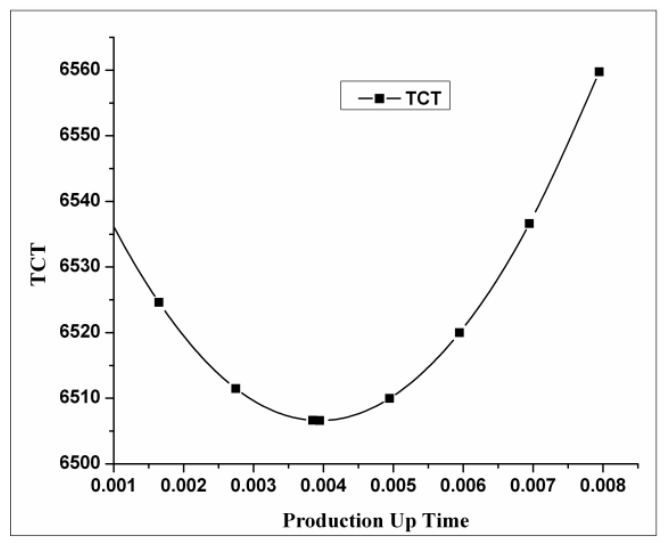

Fig. 2. $\mathrm{T}_{2} \mathrm{~V} / \mathrm{s} \mathrm{TC}$

\section{NUMERICAL \& SENSITIVITY ANALYSIS.}

Using numerical illustrations Sensitivite analysis was performed and validated with numerical data of Ardak et al [1]. Let, set up cost = Rs.30 per cycle, $\mathrm{Q}=2500$ items in unit time, $\mathrm{R}=$ 1200 items in unit time, $\alpha=0.5, \theta=0.1$, $\mathrm{a}=2 \mathrm{~b}=1.5$. The optimum value of $\mathrm{T}_{2}$ can be found, as the total cost function is convex (Fig. 2). The optimum value of $\mathrm{T}_{2}$ is 0.00395 . The optimum total cost per unit time is $\mathrm{TC}=$ Rs.6506.44. Analysis is carried out by varying time a time and keeping others constant.
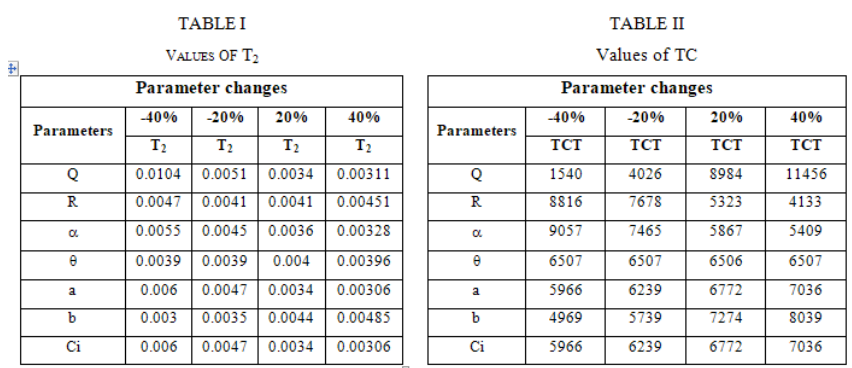

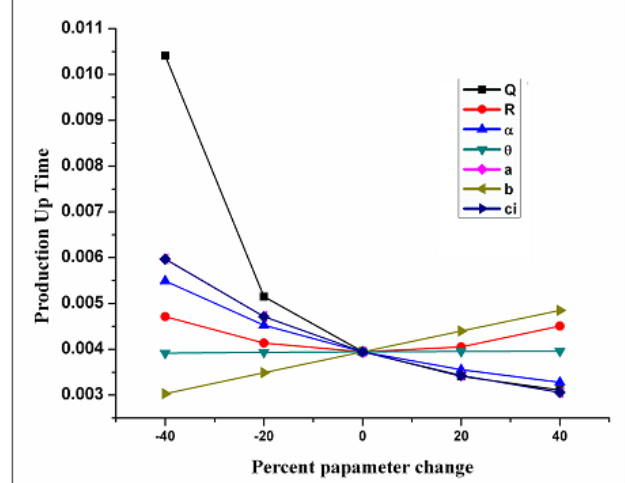

Fig.3. $\mathrm{T}_{2}$ V/S Parameter Change

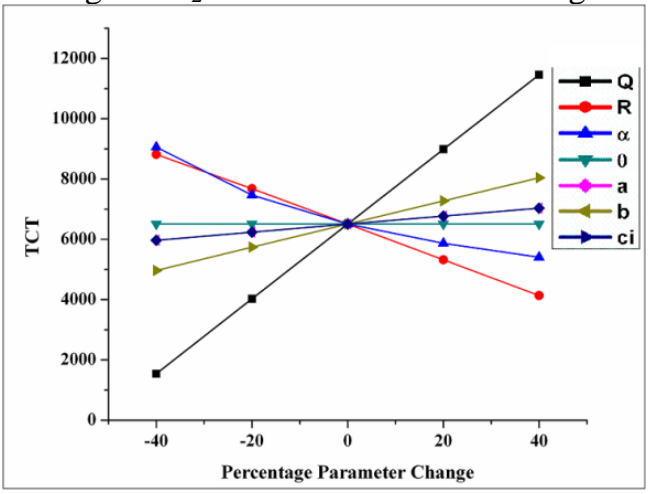

Fig.4 TCT v/s Parameter change Inventory buildup time is much sensitive to rate of production. Fig. 3 shows that inventory carrying cost and demand parameter has moderate effect on inventory buildup time. Deterioration has very linear effect. As the rate of production increases from $-40 \%$ to $-20 \%$, increases the inventory and hence demand as demand is inventory dependent. Inspection cost is a decreasing function of buildup time.

From fig 4 it can be commented that, total cost per unit time is most significant to production rate inventory dependent consumption and demand. Increase in Inspection cost and holding cost increases the total cost

TABLE III Sensitivity analysis of $\mathrm{T}_{3}$

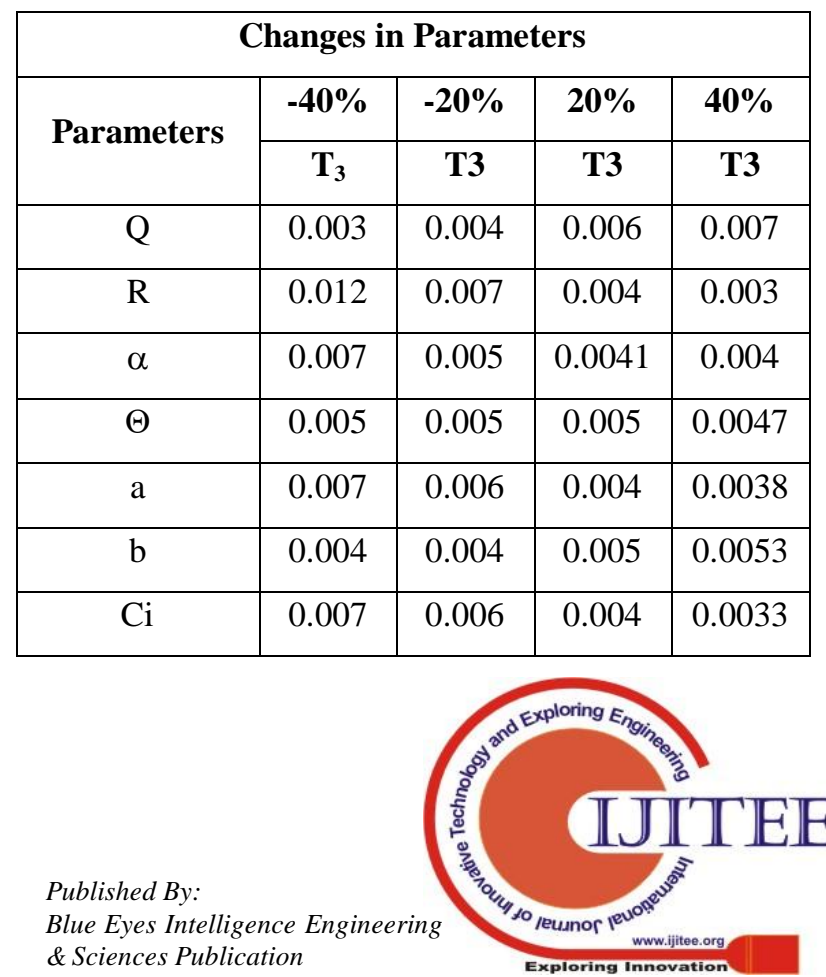


TABLE IV Values of holding cost for consumption rate

\begin{tabular}{|c|c|}
\hline \multicolumn{2}{|c|}{ parameter } \\
\hline $\boldsymbol{\alpha}$ & $\mathbf{I H}$ \\
\hline 0.3 & 1951 \\
\hline 0.4 & 1545 \\
\hline 0.5 & 1301 \\
\hline 0.6 & 1138 \\
\hline 0.7 & 1022 \\
\hline
\end{tabular}

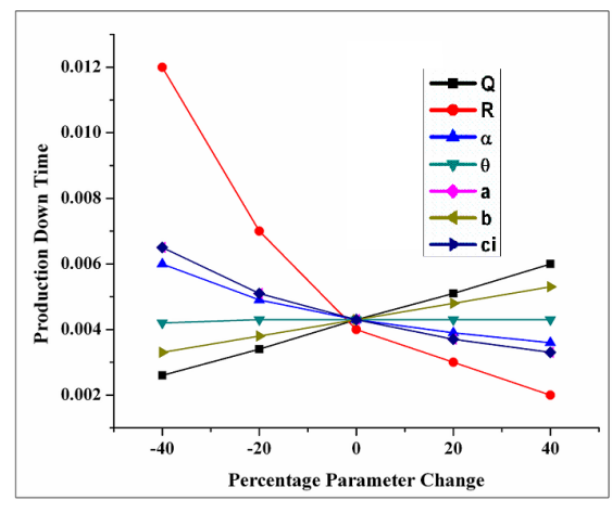

Fig. $5 \mathrm{~T}_{3}$ v/s change in parameter

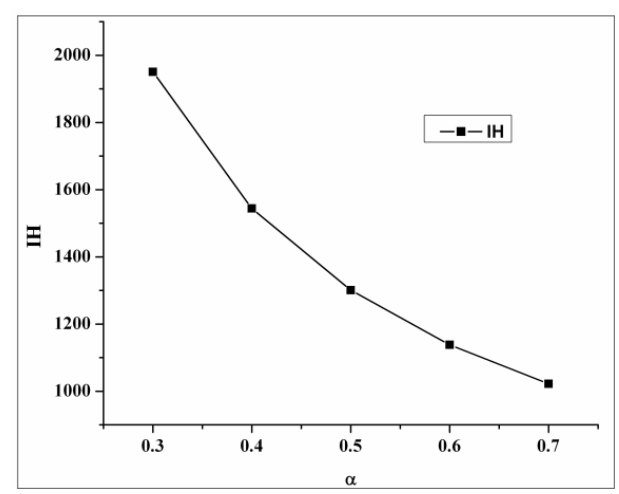

Fig 6. Demand v/s Holding cost

Fig 5 shows that increase in demand, decreases the down time. While less effect of production rate and holding cost on down time. Down time increases by increase in holding cost. It means if proper holding arrangement is not available then perishable items deteriorates and lost its quality, which decreases the demand. Fig. 6 shows that proper selection of inventory consumption rate decreases the holding cost.

\section{CONCLUSIONS}

Theoratical inventory control model was developed, considering holding cost as time dependent and demand as inventory dependent. Holding cost can be controlled by proper selection of inventory dependent consumption rate parameter. This indicates that buying capacity of customer can be increased. Inventary managers can use this model effetively for perishable items.

\section{REFERENCES}

[1] Ardak P. S. Borade A. B.( 2017), 'An EPQ Model with time dependent holding cost and varying deterioration rate', International Journal of Mechanical Engineering and Technology, Volume 8, Issue 8,August 2017, pp 958-966
[2] Ardak P.S. Borade A.B., Reneta S.B.(2017), 'An EPQ Model For Deteriorating Items with mix demand pattern', International Journal of Mechanical Engineering and Technology, Volume 8, Issue 6, June 2017, pp. 59-69 .

[3] Ardak P. S., Borade A.B, 'An EPQ Model with Varying Rate of Deterioration and Mixed Demand Pattern.', International Journal of Mechanical and Production Engineering Research and Development, Vol. 7, Issue 5, Dec 2017, 423-432

[4] DEEPA, N., INDUMATHI, V., \& BALAJI, P. INVENTORY MANAGEMENT PRACTICES FOLLOWED IN COCONUT OIL MILLS IN WESTERN TAMIL NADU.

[5] Jinn ,T.T., Liang,Y. O., Mei, C. C., (2005) A EOQ model for deteriorating items with power form stock dependent demand, Information and Management science, 16, Number 1 pp 1-16.

[6] Behrouz ,A. N., Babak, A. EPQ model with depreciation cost and process quality cost as continuous functions of time. International Journal of Industrial Engineering 5, (8), 77-89,2009.

[7] DavidW. Pentico, Matthew J. Drake, Carl Toews, The deterministic EPQ with partial backordering:Anewapproach, International journal of Management Sciences, Omega 37,624 - 636,2009.

[8] Ravichandran, N. A Study On Inventory Management With Reference To Leading Automobile Industry. International Journal of Management, Information Technology and Engineering, 15.

[9] Rosenblatt, M., and Lee,H.L., (1986),Economic Production Cycles with Imperfect Production Processes, IJE Transaction,.pp 48-55.

[10]Jinn,T. T., Liang, Y.O., Chun,T.C., (2005) , Deterministic economic production quantity models with time varying demand and cost, Applied Mathematical Modeling, 26,pp 987-1003. Elsevier.

[11]Chung,H,C.,(2009) , The modified economic manufacturing quantity model for product with quality loss function, Tamkang Journal of Science and Engineering, 12, Number 2,pp 109-112

[12]Kaur, M. (2017). Inventory and Working Capital Management: An Empirical Analysis of Indian Textile Companies. IMPACT: International Journal of Research in Business Management (IMPACT: IJRBM) ISSN (P), 2347-4572.

[13]Yuanshyi,P.C., (2003), Determining the optimal lot size for the finite production model with random defective rate, the rework process and backlogging, Engineering Optimization, 35, Number 4, pp 427-437.Taylor \& Francis.

[14]Mishra, S.S., Singh, P.K.,(2011) , A Computational approach to EOQ model with power form stock dependent demand and cubic deterioration, American journal of operation research, 1,Number1,pp 5-13.

[15]Shetty, P. K., \& Kamath, R. C. (2018). A study of inventory management at manufacturing Industries in rural india. International Journal of Mechanical and Production Engineering Research and Development, 9(1), 73-80.

[16]Nita, H.S., Amisha,R.P.,(2011), Integrated inventory models with two level credit policy and a price negotiation scenario for price sensitive stock dependent demand, International journal of industrial engineering computations, 2, pp 657-670. Growing Science.

[17]Gede, A. W., Hui, M. W. Production Inventory Models for Deteriorating Items with Stochastic Machine Unavailability Time, Lost Sales and Price Dependent Demand." Jurnal Teknik Industri, 12, (2), 61-68,2010.

[18]Khedlekar,U.K., A disruption production model with exponential demand". International Journal of Industrial Engineering Computations ,3, 607-616,2012.

[19]Thakkar, B., \& Parikh, P. AN INVENTORY ON DIVERSITY AND DISTRIBUTION PATTERN OF HYMENOPTERAN INSECTS IN GUJARAT, INDIA.

[20]Kuo,L.H. An EPQ model with set up cost and process quality as function of capital expenditure". Applied Mathematical Modelling,31,10 -17,2007.

[21]Jui-Jung Liao, Kuo-Nan Huang, Deterministic inventory model for deteriorating items with trade credit financing and capacity constraints, Computers \& Industrial Engineering, vol. 59, pp. 611-618, 2010.

[22]YASSA, R. I., \& IKATRINASARI, Z. F. DETERMINATION OF MULTI-ITEM INVENTORY MODEL WITH LIMITATIONS OF WAREHOUSE CAPACITY AND UNIT DISCOUNT IN LEADING GARMENT INDUSTRY IN INDONESIA.

[23]Yu-Chung Tsao, Managing multi-echelon multi-item channels with trade allowances under credit period, Int. J. Production Economics, vol. 127, pp. 226-237, 2010.

[24]Jie, M., Yong, W.Z., Gui, Q.L., Sheng, D.W. An EPQ model for deteriorating items with inventory level dependent demand and permissible delay in payments". International Journal of Systems Science, 43(6), 1039-1053,2012

\section{Published By:}

Blue Eyes Intelligence Engineering 